\title{
Ángel Escobar, una poética de la fuga
}

\author{
Lucía PUPPO \\ Universidad Católica Argentina / CONICET
}

\section{RESUMEN}

En el panorama de la poesía cubana reciente se destaca la obra iconoclasta y desesperada de Ángel Escobar (Sitiocampo, 1957-La Habana, 1997). Este trabajo propone un análisis de los recorridos físicos y simbólicos que protagoniza el sujeto poético en los textos de Escobar, en principio identificado con la figura del caminante urbano. Con el fin de plantear las bases de una poética de la fuga en los textos del autor cubano, se examinarán los siguientes factores: la sintaxis espacial que instauran los recorridos y las diversas estrategias discursivas mediante las cuales se transgrede esa lógica, las figuras retóricas que dan cuenta del dinamismo, los ropajes metafóricos que asumen los desplazamientos, el estatuto nómade del sujeto y la inscripción poética del cuerpo en el lenguaje visceral de los textos.

Palabras clave: Ángel Escobar, poesía cubana, siglo XX, espacio, fuga.

\section{Ángel Escobar, a Poetics of Fugue}

\begin{abstract}
The iconoclast and desperate works of Ángel Escobar (Sitiocampo, 1957- La Habana, 1997) stand out in the map of recent Cuban poetry. This paper analyzes the physic and symbolic routes of the poetic subject in Escobar's texts, usually identified with the figure of the urban walker. With the aim of describing a poetics of fugue in the Cuban author's texts, we shall examine, among other aspects: the spatial syntax introduced by the subject's routes and the discursive strategies that transgress it, the rhetoric figures that account for dynamism, the metaphors assumed by the routes, the nomad statute of the subject and the poetic inscription of the body in Escobar's visceral language.
\end{abstract}

Key words: Ángel Escobar, Cuban poetry, Twentieth Century, space, fugue.

SUMARIO: 1.Semiosis espacial, tránsito y poema. 2.De la caminata urbana a la fuga del Yo. 3.Las transgresiones a la sintaxis espacial. 4.Tres modalidades de la fuga: el naufragio, la caída y la inmovilidad. 5.A modo de conclusión: el poeta como "pasajero total".

\section{Semiosis espacial, tránsito y poema}

Es sabido que Michel De Certeau distinguió el "mapa" y el "recorrido" como dos grandes tipos de estructuraciones del espacio. Mientras que el primero remite a lo visto y a "un asentamiento totalizador de observaciones", el segundo implica un hacer, "una serie discursiva de operaciones" en el campo de un sistema (De Cer- 
teau, 2000: 131-132). La cartografía ordena y jerarquiza; en cambio, el modelo del recorrido focaliza en el dinamismo azaroso de un sujeto que transita el espacio. Si pensamos la experiencia urbana bajo esta perspectiva, cada caminante forma "frases imprevisibles" en su recorrido (XLIX) y actúa mediante "procedimientos que, lejos de que los controle o los elimine la administración panóptica, se refuerzan en un ilegitimidad proliferadora" (108). A partir de esta lógica del desplazamiento me interesa leer la obra de Ángel Escobar (Sitiocampo, 1957-La Habana, 1997), situada entre las más impactantes y originales de la poesía cubana y latinoamericana de fines del siglo veinte.

Tras haber permanecido durante años como un autor de culto, conocido por sus amigos y una selecta minoría de escritores-lectores cubanos y chilenos, poco a poco la figura y la obra de Escobar comenzaron a ser advertidas en círculos más amplios. ${ }^{1}$ Intensa, compleja y profundamente innovadora, su poesía hace suya la humanidad sangrante de César Vallejo para insertarse en la tradición iconoclasta de Virgilio Piñera. Su lenguaje agudo y procaz no escatima alusiones a la infancia pobre en un bohío, el asesinato de la madre a manos del padre y el sufrimiento causado por la esquizofrenia, un anecdotario trágico que culmina con el suicidio del autor, ocurrido el 14 de febrero de 1997.

Sin embargo, se trata de una obra que no se agota en el mito autobiográfico, aunque ciertamente la breve vida de Escobar resulta iluminadora para comprender el clima de desazón que vivió la población cubana en el llamado "Período Especial en Tiempos de Paz", a comienzos de los noventa. La esperada aparición de su Poesía completa (La Habana: Ediciones Unión, 2006) terminó de consolidarlo como uno de los grandes poetas finiseculares, y día a día se incrementan los estudios referidos a su obra, que además de poesía comprende una pieza teatral y un volumen de cuentos.

La poesía de Escobar presenta dos actitudes o tendencias eminentemente espaciales. Por un lado, una concepción espacial del Yo, el cuerpo y la escritura: "Mi cuerpo, rincón solo que aguarda" (Escobar, 2006: 312)2; "Estoy acostado ya / sobre esta página" (410). Por otro lado, en sus textos se impone la voluntad consciente

${ }^{1}$ Entre 1991 y 1995 Escobar viajó a Chile, invitado por la Sociedad de Escritores de ese país (Guajardo 1999). A temprana edad, en 1977, Escobar ganó el Premio David, de la UNEAC, con Viejas palabras de uso. Luego obtuvo el Premio de Poesía Roberto Branly (UNEAC) por Epílogo famoso (1985). Si los dos primeros libros recibieron el elogio y la aprobación de la crítica oficial, a partir de La vía pública la poesía de Escobar fue alejándose de los cánones preestablecidos y ganando en oscuridad y concentración, en un proceso paralelo al de la esquizofrenia que lo sometía a diversos tratamientos e internaciones.

${ }^{2}$ De aquí en más, todos los números de página de poemas de Escobar corresponderán a la ya mencionada edición de Poesía completa (2006). 
por parte del sujeto poético de recorrer y volcar en el papel sus brutales experiencias en "la ciudad podrida" (402).

La configuración distópica de La Habana reposa principalmente sobre cuatro ejes: el registro visual de los signos urbanos, leídos en clave pictórica (expresionista, cubista y onírica); las isotopías de la podredumbre, la desintegración y el filo, que tematizan los tópicos asociados al dolor, la enfermedad y la muerte; la percepción claustrofóbica de los espacios cerrados, cuyos epítomes resultan el hospital y el manicomio; $\mathrm{y}$, finalmente, la idealización del campo lejano, asociado a la tierra natal (Puppo, 2011).

Según De Certeau, un lugar cuenta una historia e, inversamente, toda historia implica algún tipo de tránsito espacial. Si el mapa recorta un espacio, el relato lo atraviesa porque es, justamente, diégesis (De Certeau, 2000:141). A la luz de este razonamiento, nos proponemos leer los "relatos" que atraviesan los textos poéticos de EscoEscobar cada vez que postulan la travesía del sujeto poético. Al explorar la dimensión diegética de esta poesía seguiremos una consigna del poeta Yves Bonnefoy quien, en su curso de poética en el Collège de France, advirtió que "todo poema esconde en su fondo un relato, una ficción" (2007: 29).

\section{De la caminata urbana a la fuga del Yo}

Resulta adecuado hablar de una trayectoria o evolución en la poesía de Ángel Escobar (Aguilera, 2001; Arcos y Rodríguez Santana, 2007), que de libro a libro fue multiplicando y concentrando sus recursos para ganar cada vez más fuerza expresiva. En los tres poemarios de la juventud -Viejas palabras de uso (1978), Epílogo famoso (1985) y Allegro de sonata (1987)- el poeta aún no ha encontrado su voz, de allí que los mismos privilegien una descripción idealizada del entorno rural. Apenas un poema sitúa al poeta enamorado en la ciudad para tomar distancia de la visión mítica que propuso Alejo Carpentier: "Vivo en un ciudad que dicen de columnas" (72).

Una fuerte impronta habanera sella la etapa media de la poesía de Escobar, que comprende los poemarios La vía pública (1987), Malos pasos (1991) y Todavía (1991). En estos textos se describe la ciudad sucia y olorosa como el territorio de la improvisación, el abandono, la acumulación kitsch y el egoísmo humano. La Habana se convierte en la ciudad medida de todas las otras, como lo da a entender Abuso de confianza (1992), un poemario que refleja el impacto de la estancia del autor en Chile.

En los textos de estos años se instala la figura del "paseante" (148), que observa con ironía el fluir de trabajadores y turistas por las calles. Confrontado por su soledad en medio de la multitud, el hablante poético experimenta la crueldad e indiferencia de la urbe: "Y por eso me dicen transeúnte, porque siempre las puertas / me dan con el trasero en pleno rostro". Esas "pedradas que lanza la intemperie" (150) justifican en ciertas ocasiones la paranoia del sujeto en la "maldita acera" (159), y en otras, la abulia que gobierna su recorrido: "mi cigarrillo repetido por las 
calles sucias" (189). La desorientación en el espacio es un índice de la crisis identitaria del hablante: "Yo estoy en esta calle que es la única del mundo / (lo son todas las calles) sin nombre ni argumento / [...] No sé si voy o vengo, si anhelo soy o asfalto. / Aquí significar no significa" (219-220).

Enumeraciones más o menos caóticas y el uso repetido de asíndeton y polisíndeton constituyen las figuras retóricas -esperables, por cierto- que dan cuenta del dinamismo del sujeto que atraviesa el espacio. De modo más original, la sincronía bullente que marca el pulso de la ciudad se manifiesta en el anacoluto, presente en cuatro poemas de La vía pública que terminan con el nexo "y", incluido entre ellos el último del libro. El coordinante que no coordina materializa la insistencia metafórica de lo precario e incompleto, así como de cierto resto que la mecánica cotidiana no logra procesar: "y lo que cada día empuja este andamiaje / hacia no sé qué límite inconexo / hacia no sé qué borde todavía inconcluso y" (162).

La tercera etapa de la poesía de Escobar se inicia con el libro Cuando salí de La Habana (1997), texto que clausura el ciclo urbano planteando ya la imposibilidad de abandonar realmente la ciudad. Se advierte un prematuro cansancio en el sujeto poético ("fatiga y ruinas", 281) que profundiza su tristeza ("no hay ciudades / donde pueda cerrar la mano sobre esta rosa negra / que sin cesar se seca", 297). La lucidez irónica alterna en este poemario con las imágenes alucinatorias, prefigurando ya el horizonte caótico donde se instalan las dos colecciones póstumas, El examen no ha terminado (1997) y La sombra del decir (1997).

En estos textos obsesivos el discurso tiende a la paronomasia y la sinestesia ("un punzón entra, lento, en las entrañas", 341; "Veo el sonido de la luz sobre el asfalto", 379). Los espacios del graffiti, el baño público y el manicomio resultan sinécdoques de lo marginal y abyecto. Ahora los desplazamientos físicos del sujeto manifiestan abiertamente la "traslación simbólica de uno a otro lugar de sí mismo" (203), como lo expresó el mismo Escobar en uno de los prólogos.

"Cuando salí de La Habana" es el extenso poema que cierra y da nombre al libro que lo contiene. En versos veloces, de ritmo entrecortado y asociaciones libres, el discurrir del hablante poético no remite tanto al espacio exterior como al movimiento ciego que empuja al sujeto hacia adelante: "Por qué todas estas ciudades enarbolan / tu fuga; hacia qué no te irás; cuánto descubres / en este silencio paridor de actos: qué, cómo transiges" (302). Personajes del pasado, muertos y muñecos pueblan los paisajes oníricos por donde avanza el poeta, en un clima de final que los acerca a la escritura de Reynaldo Arenas: "Entona tu canción antes / de que anochezca de súbito toda, sí, toda / la era" (305).

Afirma reiterativamente el sujeto de Escobar: "Corro y me desbarato" (274), "corro y me destartalo" (284). Como lo señaló Efraín Rodríguez Santana, en su poética "la fuga -la fugacidad- se convierte en categoría de lo insospechado, lo oculto, lo oscuro, lo que se revela sólo en el proceso creativo" (1999: 70). Esta necesidad de partir responde a una urgencia por aliviar el sufrimiento de un Yo escindido: "estoy en otra parte" (345), "Hoy salí, salgo y saldré de mí" (391). A medida que avanza 
cronológicamente, la obra del poeta afrocubano se hunde cada vez más en las tinieblas de una "mente rota" (203), al punto de que, en su último cuaderno, "fuga quiere decir disolución personal, suicidio" (Rodríguez Santana 1999: 92).

\section{Las transgresiones a la sintaxis espacial}

Una hipótesis inicial de este trabajo es que los recorridos del sujeto escobariano instauran una determinada sintaxis o lógica del espacio en los textos poéticos. Ahora bien, hemos comprobado que ese "relato" que cuentan los poemas muchas veces refiere a un recorrido figurado o simbólico que, además, puede resultar ambiguo e inestable. En este punto resulta iluminador un estudio del semiólogo esloveno Marko Juvan (2004) acerca de las transgresiones a la sintaxis espacial que se producen en los textos literarios.

Juvan señala que todo espacio representado en la literatura presupone tanto una delimitación exterior como una estructura interna coherente. Ambos factores determinan la sintaxis espacial, es decir, las estructuras hipo o paratácticas de relaciones inter-espaciales. Pero más allá de esta lógica, en los textos literarios suelen generarse "espacios de transgresión", que pueden ser definidos como aquellas "áreas donde diferentes espacios se disuelven, se amalgaman o cubren unos a otros". ${ }^{3}$ Mediante estos movimientos, los espacios referenciales adquieren una naturaleza imaginaria, fantasmática y móvil.

Juvan distingue cuatro tipos de fuerzas transgresivas de la sintaxis espacial. La primera de ellas es la "transgresión figural", que es producida por una metáfora, una metonimia o cualquier tropo. Este procedimiento es habitual en la escritura de Escobar, como lo evidencia el poema "Hábitat":

Vivo en la punta de un cuchillo.
Si resbalo hasta el filo, sajado
seré antes de llegar al cabo hondo.
Si resbalo por el lomo, me haré añicos
después del mango sucio. Si por los planos
caigo, astillas seré en los bordes atornillados...

Este texto aporta una imagen espacial inédita, que surge del conflicto entre la dimensión literal y el sentido figurado de las construcciones adverbiales. Al postular el cuchillo como "hábitat" del sujeto poético, el poema da cuenta -con terrible síntesis- de una situación existencial precaria y sin salida: de una vida al borde del abismo, diríamos recurriendo a otra imagen espacial.

\footnotetext{
${ }^{3}$ Traduzco literalmente del texto de Juvan, publicado en inglés.
} 
La segunda forma de transgresión relevada por Juvan es "el palimspesto espacial", que ocurre cuando los fragmentos de distintos lugares se hacen presentes, son recuperados por la memoria o bien imaginados en una sola secuencia que los superpone y los mezcla, al modo proustiano. Esto es visible en el poema "Cartilla borrada", de La sombra..., donde el hablante poético comienza situándose en un escenario rural, en "un campo de algodón", sentado "entre el millo", pero luego indica que toma un tren para llegar a las ciudades (390). A continuación leemos en el poema:

\author{
... Mi galantería \\ con el tiempo y el espacio es rechazada \\ como me rechazan la colegiala y el místico - \\ dejándome en esta calle que no conduce a nada. \\ Estos edificios me hacen añorar la malva - \\ cuando tuve la malva, me convertí en la nostalgia \\ de pueblos y edificios polvosos venideros. \\ Corriendo entre pastizales, ya tenía el recuerdo \\ de la náusea, la precariedad de la angustia, \\ y el tartaleo de la melancolía. Ante este jueves \\ no puedo decir lo siento, y que algo o alguien \\ me escuche. Sólo veo mi silencio, sólo sé de él, \\ y sé que ese maldito espejo en mí me miente. (390)
}

Aquí la transgresión espacial -la rechazada "galantería con el tiempo y el espacio"- está pautada por las asociaciones, o mejor dicho, las disociaciones de imágenes. En el tramo final del poema el espacio diegético urbano se superpone nuevamente con el ámbito rural evocado por el deseo y la memoria. Y el espacio referencial exterior ("estos edificios") se funde con el espacio imaginario interior ("ese maldito espejo en mí").

A un tercer tipo de transgresión a la lógica espacial Juvan la denomina, apelando a la terminología de Lotman, "explosión textual". Esta tiene lugar en escrituras modernas carentes de coherencia y conectores lingüísticos, que dejan ambiguos los límites entre los espacios exteriores y las estructuras subjetivas. La yuxtaposición espacial surge porque se desplaza el punto de vista y se desterritorializa la posición del sujeto. Resulta un ejemplo de explosión textual el poema "Violín de Brindis de Sala" (392), también incluido en La sombra...:

Estas flores que rezo anticipan a Polímedes.

Por hoy, soy yo quien tiene la medida

de todas las ciudades -veo una verja

a la que el sol le da, y me visita Dante.

Ese rumor escrito en la plegaria de Plácido

está en mí -juntos hemos estado en jardines

imposibles. Nada ha podido evitar nuestra charla.

Hay embarcaderos sucios, rincones donde se solazan 
las ratas -palacios, mármoles, platería

donde él aplasta conmigo un cigarro furtivo.

Y a Milanés lo quiero, y lo ofrezco verso a mi prima

adolescente -tórtola no cautiva. Y a Manzano

le digo que soy él -juntos miramos el cielo

indescifrable de un París comedido. Viene a mí

Luaces -somos el dos cumplido, estatua

del decir, el entorno que cena en Boticelli-

nace una Venus, y todos somos Luaces y Zenea,

estamos llorando por Fidelia. ... (392)

Los primeros versos instalan la ambigüedad textual a partir del juego de palabras en torno al nombre de Polímedes (escultor de la Antigüedad) que, por el recurso de la falsa etimología, se asocia con "la medida de todas las ciudades". Como explica Francisco Morán en su comentario de este poema, el yo escobariano se identifica, entre otros, con Dante en el destierro, con Plácido, un poeta mulato fusilado en la conquista española, y con Francisco Manzano, poeta y esclavo del siglo diecinueve (2008: 385). El contexto espacial del hablante poético "explosiona" en una sucesión de ciudades del pasado y escenarios pictóricos; la serie fantástica concluirá luego ante la mención del cotidiano Malecón habanero, donde el sujeto mira pasar los barcos (393).

Juvan asocia el cuarto y último tipo de transgresión espacial con la intertextualidad entendida como "la práctica de transponer, yuxtaponer y mezclar espacios semióticos heterogéneos, no sólo representados en el mundo textual sino también evocados por formas lingüísticas o genéricas en la superficie textual". Citas, alusiones, collages, pastiches y parodias constituyen materiales frecuentes en la poesía de Escobar. Como lo destaca el semiólogo esloveno, estas formas intertextuales favorecen la transposición de los lugares abordados por la literatura junto con las impresiones, registros, voces y códigos ideológicos asociados a ellos. Al introducir segmentos de un discurso ajeno, las prácticas intertextuales permiten incorporar en un nuevo texto las huellas del contexto comunicacional y del espacio cultural y sociogeográfico en el que funcionaba originariamente ese discurso.

La intertextualidad del espacio escobariano se vuelve patente en un poema fundamental incluido en Abuso de confianza, "Apuntes para una biografia de Helene Zarour". Este largo y doloroso texto rinde homenaje a una militante de izquierda chilena que, a mediados de los años setenta, fue apresada y torturada en Villa Grimaldi, un centro clandestino montado por la dictadura de Augusto Pinochet, en la ciudad de Santiago. Sin seguir un orden lineal o cronológico, el texto evoca fragmentos de la vida de Helene Zarour privilegiando dos espacios cruciales: la sala de torturas, a cargo del civil Osvaldo "Romo" Mena, y el mar donde, años después, Helene decidió quitarse la vida (214-216). El interior horroroso de ese "sótano con gritos" y la vastedad libre del paisaje marino establecen un peculiar contrapunto 
entre tensión y lirismo, duplicando en espejo la distancia entre la inocencia luminosa de la víctima y la violencia oscura de sus victimarios. ${ }^{4}$

En el poema los cronotopos de la prisión y el mar se configuran, respectivamente, mediante descripciones de la tortura ("antes de que le astillen el cráneo contra el muro") y una alusión a "Alfonsina y el Mar", la canción que Helene entonaba en cautiverio sin saber que con ella anticipaba su propio suicidio ("No se ha ido al mar. / Ahora escuchamos una canción en la que el mar / no es él, sino un olvido sudamericano"). ${ }^{5}$ De este modo, el texto une simbólicamente la muerte de Helene y la de la argentina Alfonsina Storni (1892-1938), que no es la única poeta aludida, pues un tercer intertexto se reconoce en el entramado del poema: "Cree creer que oyó / que hubiera sido reina" (215). Se trata de una cita del famoso poema "Todas íbamos a ser reinas", de Gabriela Mistral. Como explica Juliet Lynd, este verso de la poeta chilena hoy puede leerse en el Parque por la Paz que se erige en las instalaciones de Villa Grimaldi, donde un jardín con esculturas recuerda a las mujeres que pasaron por allí en los años del terror (Lynd 2010: 132).

Los cuatro casos de transgresiones espaciales examinados revelan complejas y diversas estrategias que cooperan en la producción de sentido. La alquimia poética escobariana recurre a tropos, superposiciones e intertextos que desterritorializan la mirada y complejizan la representación de los espacios. De ese modo las secuencias narrativas alteran su lógica causal, produciendo saltos y vacíos que invitan al trabajo activo de los lectores. Ficción y no ficción acuden en múltiples registros y tonos que buscan dar cuenta del horror, ya sea en el plano íntimo de la mitología personal, ya sea como denuncia de las distintas formas de violencia que conoció un siglo propenso a "disfrazarse / de circo sigiloso" (153).

\section{Tres modalidades de la fuga: el naufragio, la caída y la inmovilidad}

Un anagrama incluido en Todavía asocia el desplazamiento del sujeto poético al imaginario acuático: "y nado y ando" (186). Trasladada al mar, la fuga deviene naufragio, motivo recurrente en la poesía y la literatura cubanas escritas a partir de $1980 .{ }^{6}$ En El examen... leemos el siguiente poema, que se inserta en la serie titulada "Sobre líneas azules":

${ }^{4}$ La fuerza expresiva de este poema le debe no poco al compromiso biográfico que asumió Escobar en él, pues Ana María Jiménez, su esposa -también de origen chileno y luego exiliada en Cuba-, fue compañera de celda de Helene y su pequeña hija (Dykstra, 2009; Lynd 2010).

5 “Alfonsina y el mar" es una zamba muy popular en Latinoamérica; su música fue compuesta por Ariel Ramírez y su letra, por Félix Luna.

${ }^{6}$ Naufragios es el título de un poemario de Antonio José Ponte (1988) y de otro de Jesús J. Barquet (1998). De más reciente aparición son Naufragio y sedición en la Isla de Juana (2001), de Jorge Salcedo; Un pedazo de azul para el naufragio (2005), de Amelia del 


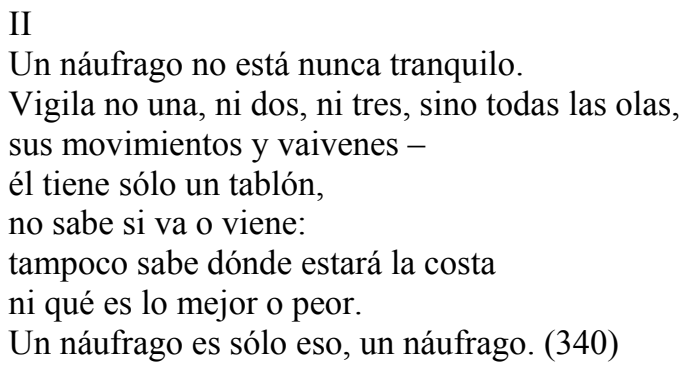

El texto describe el temor, la inseguridad y el constante estado de alarma al que se somete el náufrago, despojado de su condición de sujeto y transformado en objeto a merced de las olas y el viento. Es lícito interpretar que, lejos del panfleto a favor o en contra del régimen castrista, el poema reflexiona acerca de las dudas y el desconcierto de quienes intentan abandonar la isla. Pero este mensaje literal se complejiza en la medida en que el náufrago resulta una metáfora de la soledad y el fracaso.

Otra vuelta de tuerca presenta "El tablón de un ahogado" (335), poema situado unas páginas antes en el mismo volumen. Al comienzo aparece la nave que se hunde como alegoría de la nación, y los náufragos, en plural, resultan ser los "huérfanos", aquellos que expulsados del sistema se aferran a su vocación de sobrevivientes. Aunque su nave perezca, los náufragos cantarán y volverán a construirla, porque son "tercos", "tienen paciencia y orgullo" y, sobre todas las cosas, los anima su fe en los augurios, "esas supersticiones que tienen los deseosos" (335). De ese modo la crisis (literal y simbólica) que designa el naufragio es confrontada por cierto optimismo social que puede proceder de la capacidad de resiliencia o voluntad de sobrevida (Salomone 2011). Lo cierto es que, en los últimos versos, el hablante escobariano se autoexcluye del grupo de los náufragos alegres y experimentados:

Se puede ser así, y se puede ser siempre, un animal de fondo: no una pistola ni un libro.

Castillo; y Cronología del vértigo y del naufragio (2007), un cuaderno publicado póstumamente de Luis Marimón. Es indudable que este motivo tradicional, que en la literatura latinoamericana encarna paradigmáticamente, en el siglo XVI, el relato de Álvar Núñez Cabeza de Vaca, se ha resignificado en el contexto cubano a partir de acontecimientos como el éxodo del Mariel (1980) y la crisis de los balseros (1994). Este tópico reaparece también en la narrativa cubana contemporánea y ha sido rastreado por Jorge Fornet (2003), María Fernanda Pampín (2010) y Margarita Zamora (2011), entre otros. 
En cada naufragio hay el vestigio de algo.

Pero yo no soy un náufrago.

Frente a la costumbre del náufrago eterno, animal habituado a subsistir con los vestigios, se ubican la "pistola" y el "libro" como dos realidades irreductibles. La muerte y la escritura parecen ser la única opción para aquel que no transige, o sea, para el que no quiere o no puede ser un náufrago.

"Tomo la barca / y vuelo" (349): estos versos, pertenecientes también a El examen..., desplazan la fuga del medio acuático al aéreo. El vuelo aparece como deseo ardiente del sujeto escobariano ("Volaré; iré, iré- / nada puede pararme, ni ese rencor oleoso / que envenena mi sangre", 313). En esta imagen podemos leer sus ansias de libertad, sin descartar la posible evocación de las proyecciones imaginarias de la psicosis o el efecto alucinógeno de algún fármaco. Por otra parte, en la tradición de la poesía mística el vuelo constituye una figura del ascenso espiritual: "Quiero volar, y vuelo; mas me acompaña / el cepo que me ciñe y aguanta" (389).

Este anhelo de elevación se relaciona estrechamente con la metáfora del ángel, inscrita en la poesía de Escobar con la punzante intimidad del nombre propio. Haciéndose eco del aforismo clásico que indicaba la interdependencia nomen omen, los versos del poeta cubano juegan con la idea de que el nombre de una persona lleva grabado su destino. ${ }^{7}$ El problema es que no resulta fácil acceder a ese destino ideal o angélico: "Si pudiera convertirme en mi nombre- / no cavaría este foso" (287). Entonces sobreviene la contraparte del vuelo, la caída: "Me incorporo y me caigo; me incorporo y me caigo cual piltrafa" (246); "Cae, cae la noche amarga... / ... Cae mi filo sordo" (284).

En el sentido más literal, caer significa sumergirse en la angustia, perder las ganas de vivir, experimentar el límite y el dolor. Pero sabemos también que la caída es un esquema o arquetipo estudiado por la antropología simbólica. En tanto que primera experiencia del miedo en el recién nacido, o de los primeros pasos en el niño, esta imagen representa para el adulto un significante brutal de la condición humana. Simboliza la derrota bajo sus múltiples formas, la pérdida de un punto de apoyo que remite tanto a los orígenes -el nacimiento- como al fin -la muerte- (Xiberras, 2002: 150-51).

${ }^{7}$ Como lo señaló Roland Barthes (1973), en la literatura el nombre propio es una "monstruosidad semántica", un "signo voluminoso" que se presta a exploración y desciframiento. Según Derrida (1984), la firma o inscripción poética del nombre pone de manifiesto la distancia entre el habla y la escritura, al punto que en el texto "la firma inventa a quien firma" (1984: 22). Para una interpretación de los juegos anagramáticos con el nombre que abundan en la etapa tardía de la poesía de Escobar, ver Puppo (2012: 269). 
Si las transgresiones a la sintaxis espacial dinamitan el relato que trazan los recorridos del sujeto escobariano, tanto el naufragio como la caída exponen su rotundo fracaso, es decir, la imposibilidad de la huida. En esta secuencia, el tercer ropaje metafórico que asumen los derroteros de la fuga es, paradójicamente, la inmovilidad. Un poema de El examen..., llamado justamente "La fuga", explora la situación del que se va sin moverse. En este texto el hablante poético se sitúa en la cocina y se observa a sí mismo salir corriendo, como un loco, hasta que vuelve a verse en la cocina "olvidando", como al comienzo del poema (317). La estructura circular confirma la peculiaridad de la fuga escobariana, que finalmente resulta deseo, actitud signo-, y contradice cualquier desplazamiento literal o concreto.

Antítesis, ironías, hipérboles y oxímoros buscan expresar los gestos angustiosos de un sujeto que insiste en "correr sentado" (372) cuando se siente "más estancado que un vicio" (375). Como lo expresó Susana Haug, la paradoja mayor es que el sujeto de Escobar "permanece en una actividad insospechada aun cuando parece estar inmóvil. Pero siempre hay movimiento, paso de un estado a otro, retroceso, salto, avance, afirmación y negación, choque y caída" (2007: 55). Ese dinamismo que conduce a la parálisis se asemeja al de los personajes de Beckett o al de una rata que deambula en un laberinto (Dykstra, 2008: 358), y revela una faceta más del desamparo.

\section{A modo de conclusión: el poeta como "pasajero total”}

Con una reciente aseveración de Adriana Marcelo iniciaremos las reflexiones finales: "Aquí lo peor no se encuentra al final, tampoco al inicio, lo terrible para Ángel Escobar es el tránsito" (Marcelo, 2011: 40). En la poesía de este autor ocupan un lugar central los recorridos físicos y simbólicos, que alteran la lógica espacial al tiempo que introducen una multiplicidad de transgresiones semánticas y vínculos intertextuales. Como variaciones de una misma melodía, los imaginarios del naufragio, el vuelo y la inmovilidad también se integran en la poética de la fuga.

El cuerpo despersonalizado, reificado y mutilado del sujeto escobariano es la "focalización enunciadora del espacio" (De Certeau, 2000: 142), el eje a partir del cual se despliega el "laberinto sensorial" que ofrece su poesía (Sáinz, 2009: 44). Con el énfasis puesto en el detritus y la escoria, el discurso de Escobar se identifica en parte con lo que Josefina Ludmer recientemente ha denominado "la palabra visceral". En esta fórmula confluyen lo personal y lo político para constituir "un género antinacional latinoamericano" propio de los años 90 (Ludmer, 2010: 160). ${ }^{8}$

\footnotetext{
${ }^{8}$ Decimos que la poesía de Escobar se identifica "en parte" con este discurso antinacional porque Ludmer lo asocia a la era de la globalización y el neoliberalismo, que en los noventa arrasaron como "pestes" en muchos de los países de América Latina. Ahora bien, el principal antecedente del "disenso nacional" en la literatura del siglo veinte es el que senta-
} 
Aferrado a su corporeidad sufriente, el hablante poético de Escobar ensaya máscaras, nombres y epítetos para volverse otro. Siempre irónicamente, elige presentarse en el rol del antihéroe: "te ves malo, enfermo, / sustituible" (268). Con un calambur se define "pobre y feroz, siempre en la periferia" (429) y en Chile encarna, con humor, al extranjero: "Porque soy de otros lares - / y feo como un mandato - / los chilenos me dicen cualquier cosa. / Las chilenas no me entregan su boca" (326). En Moscú su negritud lo vuelve sospechoso (430), pero la condición de desterrado (337) y forastero (316) parece anterior a cualquier desplazamiento geográfico.

Buena parte de la poesía de Escobar puede ser leída como "un recorrido vasto por zonas del hombre esquizofrénico" (Rodríguez Santana, 2002: 9), pero como recuerda Pedro Marqués de Armas (2001), esta perspectiva no debería hacernos olvidar que su literatura abrió innovadoras y prolíficas vías de escape. En sus textos el poeta es el "pasajero total" (187), acertada fórmula para describir al nómade de nuestro tiempo que se mueve "en un espacio abierto, indefinido" (Deleuze y Guattari 1980: 385). Como mensajero de ubicuidad, el nuevo nómade se asocia a la figura tradicional del ángel (Westphal, 2007: 53-54); sólo que en el caso de Escobar se trata de un ángel herido, cotidiano y burlón, que contempla con "maquinal desidia" sus "alas rotas" (412).

\section{BIBLIOGRAFÍA}

AGUILERA, Carlos Alberto.

2001 "Funny papers. Apuntes sobre la poesía de Ángel Escobar", en Efraín Rodríguez Santana (comp.), Ángel Escobar: el escogido. Textos del coloquio homenaje al poeta Ángel Escobar (1957-1997). La Habana: Ediciones Unión, pp. 137-148.

ARCOS, Jorge Luis y Efraín RODRÍGUEZ SANTANA.

2007 "Cartas sobre dos poetas suicidas. Ángel Escobar y Raúl Hernández Novás", Encuentro de la cultura cubana, n 45-46, Verano/otoño 2007, pp. 50-66.

ron los escritores austríacos Thomas Bernhard, Peter Handke y Elfriede Jelinek (Ludmer, 2010: 167-168). En el caso de Escobar, no podemos obviar que su obra se inserta en la tradición iconoclasta de la poesía cubana, que tuvo en Virgilio Piñera uno de sus mayores exponentes (Morán, 2000; Rodríguez Gutiérrez 2008). 
BARTHES, Roland.

1973 "Proust y los nombres", en El grado cero de la escritura, seguido de Nuevos ensayos críticos. Buenos Aires: Siglo XXI, pp. 171-190.

BONNEFOY, Yves.

2007 Lugares y destinos de la imagen. Un curso de poética en el Collège de France (1981-1993). Buenos Aires: El cuenco de plata.

DE CERTEAU, Michel.

2000 La invención de lo cotidiano. 1. Artes de hacer. México: Universidad Iberoamericana.

DELEUZE, Gilles y Félix GUATTARI.

1980 Mille plateaux, Capitalisme et schizophrénie 2. Paris : Éditions de Minuit.

DERRIDA, Jacques.

1984 Otobiographies. L'enseignement de Nietzsche et la politique du nom propre. Paris: Galilée.

DYKSTRA, Kristin.

2008 '"Do I maybe have the biography of a hero'. Notes on Ángel Escobar", en Mandorla, Nueva Escritura de las Américas/New Writing from the Americas, Issue 11, pp. 121-130.

2009 "Poems by Ángel Escobar", en In translation (junio). URL: http://intranslation.brooklynrail.org/spanish/poems-by-angelescobar. Consultado el 2 de mayo de 2011.

ESCOBAR, Ángel.

2006 Poesía completa. La Habana: Ediciones Unión.

FORNET, Jorge.

2003 "La narrativa cubana entre la utopía y el desencanto", Hispamérica, Año $32, n^{\circ}$ 95, pp. 3-20.

GUAJARDO, Ernesto.

1999 “Ángel Escobar en Chile”, en AA. VV./Colectivo Literario La Cópula, Déjame ser tu Orilla. Homenaje a Ángel Escobar. Santiago de Chile: Ediciones La Cópula, pp. 102-118.

HAUG, Susan.,

2007 “Ángel Escobar o los modos de alcanzar el infinito”, La Siempreviva (2), pp. 53-56.

JUVAN, Marko.

2004 "Spaces of intertextuality / the intertextuality of space", en Jola Škulj y Darja Pavlič (eds.), Literature and Space.Spaces of transgressiveness. Liubliana: Slovenian Comparative Literature Association. URL:

http://sdpk.zrc-sazu.si/PKrevija/2004-Literatur\&Space.htm Consultado el 31 de mayo de 2010. 
LUDMER, Josefina.

2010 Aquí América Latina. Una especulación. Buenos Aires: Eterna Cadencia.

LYND, Juliet.

2010 "Reflections on a Conversation with Ana María Jiménez, Wife of Ángel Escobar", Sirena: poesía, arte y crítica, 2010:2, pp. 126-136.

MARCELO, Adriana.

2011 "Sangre, sinceridad y llamas de Ángel Escobar", La Siempreviva, $\mathrm{n}^{\circ}$ 12, pp. 34-42.

MARQUÉS DE ARMAS, Pedro.

2001 "El gran salto hacia afuera", en Efraín Rodríguez Santana (comp.), Ángel Escobar: el escogido. Textos del coloquio homenaje al poeta Ángel Escobar (1957-1997). La Habana: Ediciones Unión.

MORÁN, Francisco.

2000 (Sel. y pres.). La isla en su tinta. Antología de la poesía cubana. Madrid: Verbum.

2008 "Ángel Escobar: la luz sobre el asfalto", en Mandorla, Nueva Escritura de las Américas/New Writing from the Americas, Issue 11, pp. 382-398.

PAMPÍN, María Fernanda.

2010 "Nuevas versiones de La Habana. La invención de la ciudad según Abilio Estévez", en Graciela Salto (comp.). Memorias del silencio: literaturas en el Caribe y en Centroamérica. Buenos Aires: Corregidor.

PUPPO, María Lucía.

2011 "Apuntes de 'la ciudad podrida': la configuración distópica de La Habana en la poesía de Ángel Escobar", Caribbean Studies, vol. 39, $\mathrm{n}^{\mathrm{o}}$ 1-2, Enero-Diciembre. 50th Anniversary, Literature Dossier, pp. 223-239.

2012 "Su líquida influencia corrosiva': de Virgilio Piñera a Ángel Escobar", en Humberto López Cruz (ed.). Virgilio Piñera. El artificio del miedo. Madrid: Editorial Hispano Cubana, pp. 257-278.

RODRÍGUEZ GUTIÉRREZ, Milena.

2008 "Contra Colón: la distopía en la poesía cubana del XIX y del XX", en Sonia Mattalía, Pilar Celma y Pilar Alonso (eds.) El viaje en la literatura Hispanoamericana: el espíritu colombino. VII Congreso Internacional de la AEELH. Madrid/Frankfurt: Iberoamericana/ Vervuert.

RODRÍGUEZ SANTANA, Efraín.

1999 "Los espacios saturados. (La obra poética de Ángel Escobar, 19571997)", en AA. VV./Colectivo Literario La Cópula, Déjame ser tu 
Orilla. Homenaje a Ángel Escobar. Santiago de Chile: Ediciones La Cópula, pp. 66-101.

2002 "Prólogo" a Ángel Escobar. Fatiga ser dos sombras. Antología poética. Madrid: Editorial Betania.

SÁINZ, Enrique.

2009 "Dos visiones sobre la poesía cubana", Cuadernos Hispanoamericanos, $n^{\circ} 706$, abril, pp. 35-58.

SALOMONE, Alicia.

2011 "Poesía, memoria y comunidad nacional. Chile y Argentina en postdictadura", Revista Sociedad y Equidad, $\mathrm{n}^{\mathrm{o}}$ 1. URL: http://www.revistas.uchile.cl/index.php/RSE/article/viewArticle/10 605/10843. Consultado el 3 de febrero de 2012.

WESTPHAL, Bertrand.

2007 "L'angelo e il nomade", Moderna: semestrale di teoría e critica della letteratura, vol. $9, \mathrm{n}^{\circ} 1$, pp. 45-54.

XIBERRAS, Martine.

2002 Pratique de l'imaginaire. Lecture de Gilbert Durand.Québec : Les Presses de l'Université Laval.

ZAMORA, Margarita (ed.).

2011 "Relatos de náufragos", La Habana Elegante, $\mathrm{n}^{\circ}$ 50, OtoñoInvierno de 2011, Dossier "Crafting Shipwrecks in Havana". URL: http://habanaelegante.com/Fall_Winter_2011/Dossier_Relatos.html Consultado el 6 de febrero de 2012 . 